\title{
A systematic review of global health capacity building initiatives in low-to middle-income countries in the Middle East and North Africa region
}

\author{
Hady Naal', Maria El Koussa ${ }^{1}$, Melissa El Hamouch', Layal Hneiny ${ }^{2}$ and Shadi Saleh*
}

\begin{abstract}
Introduction: Low-and Middle-Income Countries (LMICS) in the Middle East and North Africa (MENA) region are facing increasing global health challenges with a reduced ability to manage them. Global Health Capacity Building (GHCB) initiatives have the potential to improve health workforce performance and health outcomes, however little is known about the GHCB topics and approaches implemented in this region. This is the first systematic review of GHCB initiatives among LMICs in the MENA region.

Methods: An academic database search of Medline (OVID), PubMed, Scopus, Embase.com, and Open Grey was conducted for articles published between January 2009 and September 2019 in English. Next, a grey literature search following a recommended search framework was conducted. Reviewed records addressed a global health topic, had a capacity building component, looked at specific learning outcomes, and reflected an LMIC in the MENA. Primary outcomes included country, topic, modality, pedagogy, and population.

Results: Reports of GHCB initiatives were retrieved from grey sources (73.2\%) and academic sources (26.8\%). Most GHCB initiatives were mainly conducted face-to-face (94.4\%) to professional personnel (57.5\%) through a theoretical pedagogical approach (44.3\%). Dominant global health themes were non-communicable diseases (29.2\%), sexual and reproductive health (18.4\%), and mental health (14.5\%). When matched against the Global Burden of Disease data, important gaps were found regarding the topics of GHCB initiatives in relation to the region's health needs. There were limited reports of GHCB initiatives addressing conflict and emergency topics, and those addressing noncommunicable disease topics were primarily reported from Egypt and Iran.

Conclusion: Innovative and practicum-based approaches are needed for GHCB initiatives among LMICs in the MENA region, with a focus on training community workers. Regional and country-specific analyses of GHCB initiatives relative to their health needs are discussed in the manuscript based on the results of this review.
\end{abstract}

Keywords: Capacity building, Global Health, Middle East and North Africa, Low to middle income countries

\footnotetext{
*Correspondence: ss117@aub.edu.lb

${ }^{1}$ Global Health Institute at the American University of Beirut, Faculty of Health Sciences at the American University of Beirut, Beirut, Lebanon

Full list of author information is available at the end of the article
} 


\section{Introduction}

Over the past few decades, the Middle East and North Africa (MENA) region has made progress in reducing rates of disease, injury, and premature death [1]. Although countries in the MENA region are prolonging the lives of their populations and limiting mortality rates, this region continues to experience significant disease burdens, coupled with a reduced capability to manage them [1, 2]. Low-to Middle-Income Countries (LMICs) in specific tend to face greater health challenges among countries in the region, largely due to their decreased resources in comparison to Higher-Income Countries (HIC) in the region. In recent years, this has been exacerbated by conflicts occurring in many countries that contributed not only in limited investment towards building the health workforce to meet the health and conflict-related needs, but additionally to an exodus of a large number of experienced health workers, further straining limited resources [3]. Although the MENA region has the third lowest density of doctors and nurses, it experiences one of the highest disease burdens after Southeast Asia and Sub-Saharan Africa [4].

Limited access to education, training, mentoring, and continuous professional development are leading contributing factors that undermine the performance and commitment of healthcare workers [5, 6]. Healthcare workers are personnel who engage in service provision or decision-making to improve health in given settings. As an example, many schools and institutions that provide health-related training and education in LMICs face important shortcomings in equipment, physical space, curricula, training materials, faculty, staff, and funding $[7,8]$. These challenges suppress efforts to improve the quality of training and to expand the diversity and number of health-related programs, which negatively affect their responses to global health threats [7]. In many cases, this also makes it challenging for them to deliver even basic health services [5]. In order to improve health outcomes among LMICs in the MENA region, it is crucial to increase the number of the healthcare workforce and to strengthen their competencies through engaging approaches. Evidence suggests that an effectively trained and deployed health workforce is positively associated with addressing many health challenges, and has the potential to improve health outcomes [9]. Furthermore, ensuring equitable access to a skilled health workforce is a critical element to achieving the health or health-related Sustainable Development Goals (SDGs). This is especially true for LMICs that lack the necessary resources to mobilize efficiently and effectively trained and distributed human resources for health [10].

Global Health Capacity Building (GHCB) initiatives aim to enhance the capabilities of individuals, organizations, and communities to work in or manage global health-related topics [11]. The field of global health is multidisciplinary, and it encompasses health issues that transcend national boundaries [12]. For example, research, practice, and education in global health may cover topics such as communicable and infectious diseases, mental health and substance, traffic and conflictrelated injuries, chronic non-communicable diseases, among others [12]. Implementing GHCB initiatives is a recommended, effective, and efficient strategy to enhance the capabilities of health workers in responding to related challenges [13]. GHCB initiatives enhance the skills, knowledge, and practices of professional and nonprofessional health workers, which may ultimately affect overall health outcomes in a given setting $[13,14]$. Despite the importance and urgency of the aforementioned, the characteristics and focus areas of GHCB efforts conducted in the MENA region among LMICs have not been documented.

The aim of the present study is to provide the first systematic review of GHCB initiatives delivered in LMICs within the MENA region. Given that GHCB is essential to improving the competency and performance of the health workforce particularly within low-resource settings, this study is important to elucidate the GHCB topics and related approaches currently being addressed in relation to health challenges in the MENA region. This is an essential step to summarize the state of the field, and to identify related strengths and weaknesses.

\section{Methods}

\section{Search strategy}

Multiple search strategies were employed in this systematic review following the Preferred Reporting Items for Systematic Reviews and Meta-Analyses (PRISMA) in order to identify GHCB initiatives implemented among LMICs in the MENA region. This included an electronic academic database search, and a thorough grey literature mapping search. The latter was based on a WHO mapping framework which is a recommended approach developed by an authoritative source to conduct a mapping exercise. In both search strategies, articles had to reflect a GHCB initiative conducted in a LMIC in the MENA region. According to the World Bank, these countries include Algeria, Djibouti, Egypt, Iran, Iraq, Jordan, Lebanon, Libya, Morocco, Syria, Tunisia, West Bank and Gaza, and Yemen [15]. We used the World Bank classification for countries in the MENA region because it is a commonly used reference to locate countries in specific geographical regions [15]. Finally, we used the global burden of disease data for priority benchmarking throughout our analysis because it is the most widely used authoritative reference for disease rates globally and regionally. 


\section{Academic database}

An electronic database search was conducted by a medical librarian (LH) using the following academic databases: Medline (OVID), PubMed, Scopus, and Embase. com, and Open Grey. The three concepts were "Global Health", "Capacity Building", and "Middle East and North Africa", and included terms such as "courses", "webinars", "training", "education", "public health" among others. The full search strategy is reported in Additional file 1. Articles were included if they were qualitative, quantitative, and mixed-methods studies written in English and published between January 2009 and September 2019. Articles had to reflect GHCB initiatives conducted in a LMIC in the MENA region (see Table 1 for definitions). Although the field of global health encompasses leadership, management, and communication programs among others, in this review we only captured those that were explicitly health-related. Articles were excluded if they did not meet these criteria, or if they did not cover a global health topic, did not provide examples or cases about capacity building approaches, and were not conducted in a LMIC in the MENA region. Editorials, opinion pieces, letters to the editor, conference abstracts, study protocols, and press releases were excluded.

\section{Grey literature search}

A thorough grey literature search was conducted by $\mathrm{MEH}$ using two steps of a WHO-developed mapping framework [18]. Since we are addressing capacity building in LMICs in the MENA region, a review of literature published in non-academic sources is vital to systematically identify such initiatives in this area. The first step included an online search of databases that have hosted GHCB initiatives, trainings, and related activities. As such, filtering was done starting with a general scoping google search for online learning databases that offered global health topics. After assessing several potential databases, we only selected those that allowed us to filter the capacity building initiatives by region so that they meet our set inclusion criteria. Accordingly, we searched for GHCB initiatives using the following databases: UNESCO, International Federation of Medical Students' Associations, Kaya, Global Health Training Center, and Relief Web. A specific set of keywords was used for the search that included the following terms: "capacity building initiative", "training programs", "global health", "developing countries", and "low-and-middle income countries". The keywords were linked with Boolean operators $<$ AND $>$ to limit the breadth of the search and ensure that all concepts were included and $<\mathrm{OR}>$ to

Table 1 Definition of Key Terms

\begin{tabular}{|c|c|}
\hline Key Terms & Definitions \\
\hline Global Health & $\begin{array}{l}\text { "Health problems, issues, and concerns that transcend national boundaries, which may be influenced by circumstances } \\
\text { or experiences in other countries, and which are best addressed by cooperative actions and solutions". [16] }\end{array}$ \\
\hline Capacity Building & $\begin{array}{l}\text { The development of knowledge, skills, commitment, structures, systems, and leadership to enable effective health } \\
\text { promotion ... [with] actions to improve health at three levels: the advancement of knowledge and skills among } \\
\text { practitioners; the expansion of support and infrastructure for health promotion in organizations, and; the development } \\
\text { of cohesiveness and partnerships for health in communities. [17] }\end{array}$ \\
\hline Population Groups & $\begin{array}{l}\text { Professional Personnel have formal education and/or training in health fields such as doctors, researchers, nurses and } \\
\text { so on. } \\
\text { Community Workers have not received formal education and/or training but have one or more qualifications in related } \\
\text { health fields to practice within their community. Examples include community health workers, community nurses and } \\
\text { so on. } \\
\text { General Public (e.g. community members, parents of school students etc....) includes individuals who do not have formal } \\
\text { education and/or training, and who do not practice in any area related to global health }\end{array}$ \\
\hline Pedagogic Approach & $\begin{array}{l}\text { Theory: Initiatives classified as training, workshop, course, or fellowship without further details on the approach. } \\
\text { Interactive: Initiatives that included } 1 \text { or more combinations of presentations, group work, activities, participatory } \\
\text { approaches, interactive discussions, open discussions, practical examples, role play, simulations etc..,... } \\
\text { Practical: Initiatives that included a practical or technical training. }\end{array}$ \\
\hline LMICs in MENA & $\begin{array}{l}\text { Countries include Algeria, Djibouti, Egypt, Iran, Iraq, Jordan, Lebanon, Libya, Morocco, Syria, Tunisia, West Bank and Gaza } \\
\text { Strip, and Yemen. }\end{array}$ \\
\hline $\begin{array}{l}\text { Global Health Topics } \\
\text { Reviewed }\end{array}$ & $\begin{array}{l}\text { Communicable Diseases (Anti-microbial resistance, immunization, malaria, other communicable diseases). } \\
\text { Non-Communicable Diseases: (Cancer, diabetes, diarrhoea, heart failure, hypertension, and nutrition). } \\
\text { Mental Health (General mental health topics, substance use, and psychosocial support) } \\
\text { Sexual and Reproductive Health (Sexually transmitted infections, maternal and reproductive health, gender-based violence, } \\
\text { and sexual harassment). } \\
\text { Health System: (Health safety, workforce development, health services, and health research). } \\
\text { Child health (Not specified). } \\
\text { Disaster \& Emergency Preparedness (Disaster medicine, disaster risk, emergency health, trauma care, and injury). } \\
\text { Epidemiology (Not specified). } \\
\text { Global Health (General global health topics). } \\
\text { Oral and Dental Health (Not specified) } \\
\text { Refugee Support (Not specified). }\end{array}$ \\
\hline
\end{tabular}


extend the reach of the search to the entirety of words with similar meaning. The second step included a google web search that aimed to locate capacity-building initiatives not identified by the databases. For the google search, reviewers used the following search term "global health training [country name]". All relevant links from the first 10 google pages were viewed and assessed for capacity building information that matched the researcher's criteria. The search for the GHCB initiatives was conducted during a period of 5 months from July 2019 until December 2019. Capacity building initiatives were included in the search if they addressed a global health topic in a LMIC in the MENA, and if they appeared within the first 10 pages of the web-based search.

\section{Data Collection \& Analysis Academic databases}

Articles were retrieved by a medical librarian (LH), imported into an Endnote file, and shared with two reviewers ( $\mathrm{HN}$ and $\mathrm{MEH}$ ) who conducted the screening process. After a calibration exercise, the two reviewers each screened the titles and abstracts of all studies based on set eligibility criteria. Full texts of all potentially eligible articles were later screened based on the same eligibility criteria. In both phases, a third reviewer (MEK) was assigned to resolve disagreements. Next, one reviewer $(\mathrm{HN})$ extracted the data.

\section{Grey literature search}

One reviewer (MEH) located the capacity building initiatives from the databases and google searches and extracted the data into an excel sheet.

\section{Analysis}

Extracted variables from both searches included objective of the initiative, global health topic, target population, country, pedagogic approach, learning modality, outcomes, and funding source. We conducted and reported a descriptive analysis of data gathered from both search strategies. The results illustrated the geographical distribution of initiatives among LMICs in the MENA region, the global health theme of the initiatives, the pedagogic approaches used, the learning modalities, and the target populations.

\section{Results}

\section{General findings}

Records included in this review ( $n=179$; see Fig. 1$)$ were mainly from grey sources (see Additional file 2) $(n=131$, 73.2\%), and included governmental and non-governmental reports of GHCB initiatives (see Table 2). With regard to records retrieved from academic sources $(26.8 \%$ of all records), out of 5972 articles screened (see Fig. 1), 244 were eligible for full-text review, and 48 articles were analysed and had their data extracted (see Table 3). Of all the reviewed records, almost all reported capacity-building initiatives were conducted face-to-face (94.4\%), and adopted online (1.7\%) or blended (2.2\%) learning modalities. Half of the reported GHCB initiatives followed a theory-based (51.4\%) pedagogic approach, whereas the rest were interactive $(30.6 \%)$, mixed theory and practice $(11.8 \%)$, or were only practical $(6.3 \%)$. The most frequent target population (see Table 1 for definitions) was professional personnel (57.5\%), followed by the general public (18.4\%) and community workers (3.9\%).

\section{GHCB topics}

The global health topics that were addressed in the capacity building initiatives included non-communicable diseases, communicable diseases, child health, disaster/ emergency preparedness, epidemiology, global health, health system, mental health, oral and dental health, refugee support, and sexual and reproductive health (see Table 1). The most addressed topics were categorized under non-communicable diseases (29.2\%), sexual and reproductive health (18.4\%) and mental health (14.5\%).

\section{GHCB topics by country}

The frequency and themes of GHCB initiatives varied by country (see Fig. 2). Iran $(N=32)$, Lebanon $(N=30)$, Egypt $(N=27)$, and Yemen $(N=19)$ reported the highest number of GHCB initiatives. In Iran, non-communicable diseases and health system topics were the most common among the reported GHCB initiatives, whereas in Lebanon GHCB topics mainly targeted mental health, sexual and reproductive health, and communicable diseases. In Yemen, the highest number of reported initiatives addressed sexual and reproductive health, similarly to Egypt who in addition to that, also commonly reported on non-communicable diseases, and emergency and disaster topics.

The least documented GHCB initiatives were derived from West Bank and Gaza $(N=9)$, Algeria $(N=7)$, Libya $(N=7)$, Syria $(N=6)$, Morocco $(N=3)$, and Djibouti $(N=1)$. In Djibouti, only one initiative was reported, and it focused on non-communicable diseases, whereas in Morocco the three reported initiatives targeted mental health, epidemiology, and non-communicable diseases. Initiatives reported from West Bank and Gaza, Algeria, and Syria primarily tackled mental health topics. The highest number of records found from Tunisia addressed sexual and reproductive health topics, and the case was similar in Libya who in addition mostly reported on health system topics. Finally, in Iraq and Jordan, retrieved records mostly targeted emergency and disaster topics, in addition to mental health. 


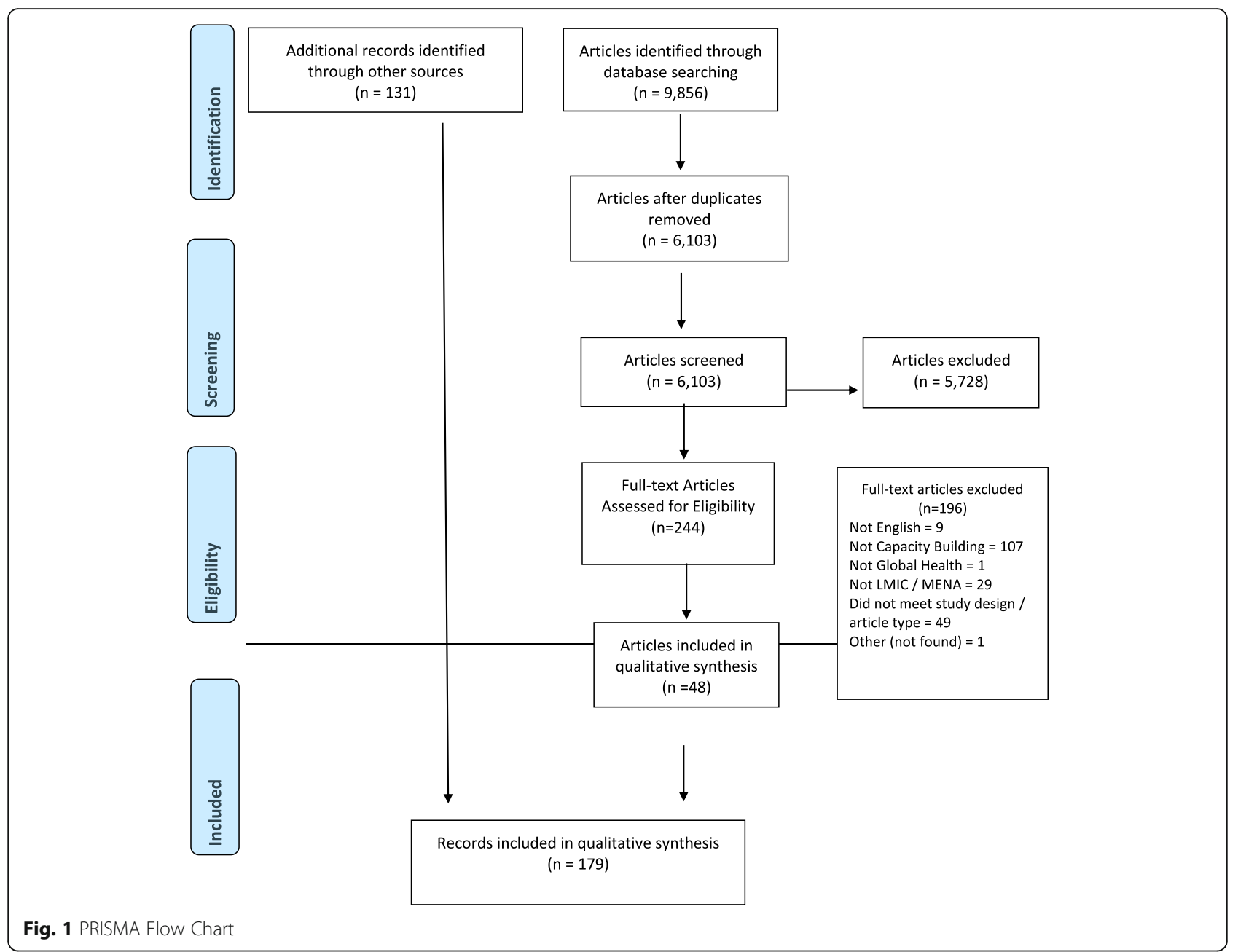

\section{Discussion}

LMICs in the MENA region experience a high burden of disease, and they have limited resources for health education and training $[1,6,7]$. Thus, they have a high need to develop a competent health workforce through GHCB initiatives in order to respond to health challenges. However, very little is known about the topics and approaches of GHCB initiatives being implemented throughout the region. In this systematic review, we summarized GHCB initiatives among LMICs in the MENA region, with a focus on the learning modality, pedagogical approaches, and global health topics. We also matched the documented GHCB topics against the Global Burden of Disease data in order to identify priority areas.

Our findings revealed that over the past decade, all of the reviewed GHCB initiatives among LMICs in the MENA region were conducted face-to-face, with the exception of a handful delivered through online or blended learning modalities. It may be important for LMICs in the MENA region to start adopting innovative learning modalities since these may have strong potential in facilitating the delivery of global health education and training especially in underserved settings with limited resources [67]. For example, there are different reports on digital resources that include online global health courses being available for worldwide use, that have been recommended as effective tools to address the shortage of qualified health workers in LMICs and low-resource settings [68]. Being relevant to some of the health challenges faced in the MENA region, it would be ideal to complement such online courses and distance-based learning platforms with locally-developed, adapted, or contextualized global health material. To that end, more research may be needed to document and evaluate these initiatives along with their effectiveness among LMICs in the MENA region.

Furthermore, our findings showed that theoretical and interactive models were the most commonly used pedagogic approaches in GHCB initiatives, as opposed to practical approaches. Notwithstanding the value of theoretical and interactive approaches, especially those that 
Table 2 Summary of Overall Findings

\begin{tabular}{|c|c|c|c|}
\hline & Grey $(n=131)$ & Academic $(n=48)$ & Total $(n=179)$ \\
\hline & $N(\%)$ & $N(\%)$ & $N(\%)$ \\
\hline \multicolumn{4}{|l|}{ Participants } \\
\hline Professional & $89(67.9)$ & $14(29.2)$ & $103(57.5)$ \\
\hline Community & $2(1.5)$ & $5(10.4)$ & $7(3.9)$ \\
\hline General & $8(6.1)$ & $25(52.1)$ & $33(18.4)$ \\
\hline Mixed & $19(14.5)$ & $4(8.3)$ & $23(12.8)$ \\
\hline \multicolumn{4}{|l|}{ Modality } \\
\hline Face-to-face & $124(96.9)$ & $45(93.8)$ & $129(96.0)$ \\
\hline Blended & $2(1.6)$ & $2(4.2)$ & $4(2.3)$ \\
\hline Online & $2(1.6)$ & $1(2.1)$ & $3(1.7)$ \\
\hline \multicolumn{4}{|l|}{ Pedagogy } \\
\hline Theory & $63(65.6)$ & $11(22.9)$ & $74(51.4)$ \\
\hline Interactive & $17(17.7)$ & $27(56.3)$ & $44(30.6)$ \\
\hline Practice \& Theory & $7(7.3)$ & $10(20.8)$ & $17(11.8)$ \\
\hline Practical & $9(9.4)$ & $0(0)$ & $9(6.3)$ \\
\hline \multicolumn{4}{|l|}{ Global Health Topics } \\
\hline Communicable Disease & $14(10.7)$ & $4(8.3)$ & $18(10.1)$ \\
\hline Child Health & $3(2.3)$ & $0(0)$ & $3(1.7)$ \\
\hline Disaster and Emergency & $15(11.5)$ & $2(4.2)$ & $17(9.5)$ \\
\hline Epidemiology & $8(6.1)$ & $2(4.2)$ & $10(5.6)$ \\
\hline Global Health / General & $12(9.2)$ & $3(6.3)$ & $15(8.4)$ \\
\hline Health System & $15(11.5)$ & $8(16.7)$ & $23(12.9)$ \\
\hline Mental Health & $18(13.7)$ & $8(16.7)$ & $26(14.5)$ \\
\hline Non-Communicable Disease & $14(10.7)$ & $14(29.2)$ & $28(15.6)$ \\
\hline Oral and Dental Health & $0(0)$ & $2(4.2)$ & $2(1.1)$ \\
\hline Refugee Support & $4(3.1)$ & $0(0)$ & $4(2.2)$ \\
\hline Sexual and Reproductive Health & $28(21.4)$ & $5(10.4)$ & $33(18.4)$ \\
\hline \multicolumn{4}{|l|}{ Countries } \\
\hline Algeria & $7(5.3)$ & $0(0)$ & $7(3.9)$ \\
\hline Djibouti & $1(0.8)$ & $0(0)$ & $1(0.6)$ \\
\hline Egypt & $19(14.5)$ & $8(16.7)$ & $27(15.1)$ \\
\hline Iran & $3(2.3)$ & $29(60.4)$ & $32(17.9)$ \\
\hline Iraq & $11(8.4)$ & $2(4.2)$ & $13(7.3)$ \\
\hline Jordan & $9(6.9)$ & $1(2.1)$ & $10(5.6)$ \\
\hline Lebanon & $27(20.6)$ & $3(6.3)$ & $30(16.8)$ \\
\hline Libya & $7(5.3)$ & $0(0)$ & $7(3.9)$ \\
\hline Morocco & $3(2.3)$ & $0(0)$ & $3(1.7)$ \\
\hline Multiple & $3(2.3)$ & $2(4.2)$ & $5(2.7)$ \\
\hline Syria & $5(3.8)$ & $1(2.1)$ & $6(3.4)$ \\
\hline Tunisia & $10(7.6)$ & $0(0)$ & $10(5.6)$ \\
\hline West Bank and Gaza & $8(6.1)$ & $1(2.1)$ & $9(5.0)$ \\
\hline Yemen & 18 (13.7) & $1(2.1)$ & 19 (10.6) \\
\hline
\end{tabular}




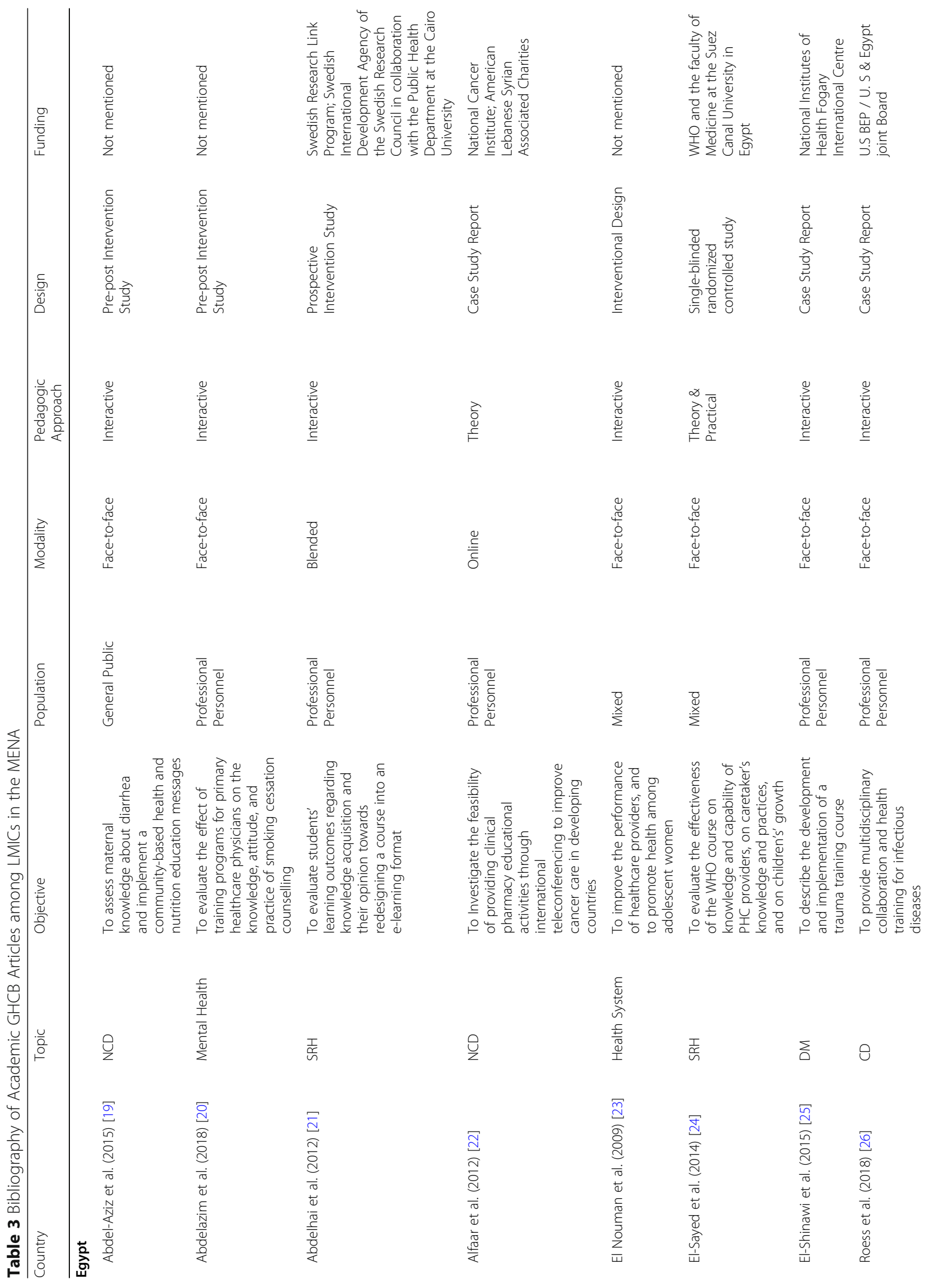




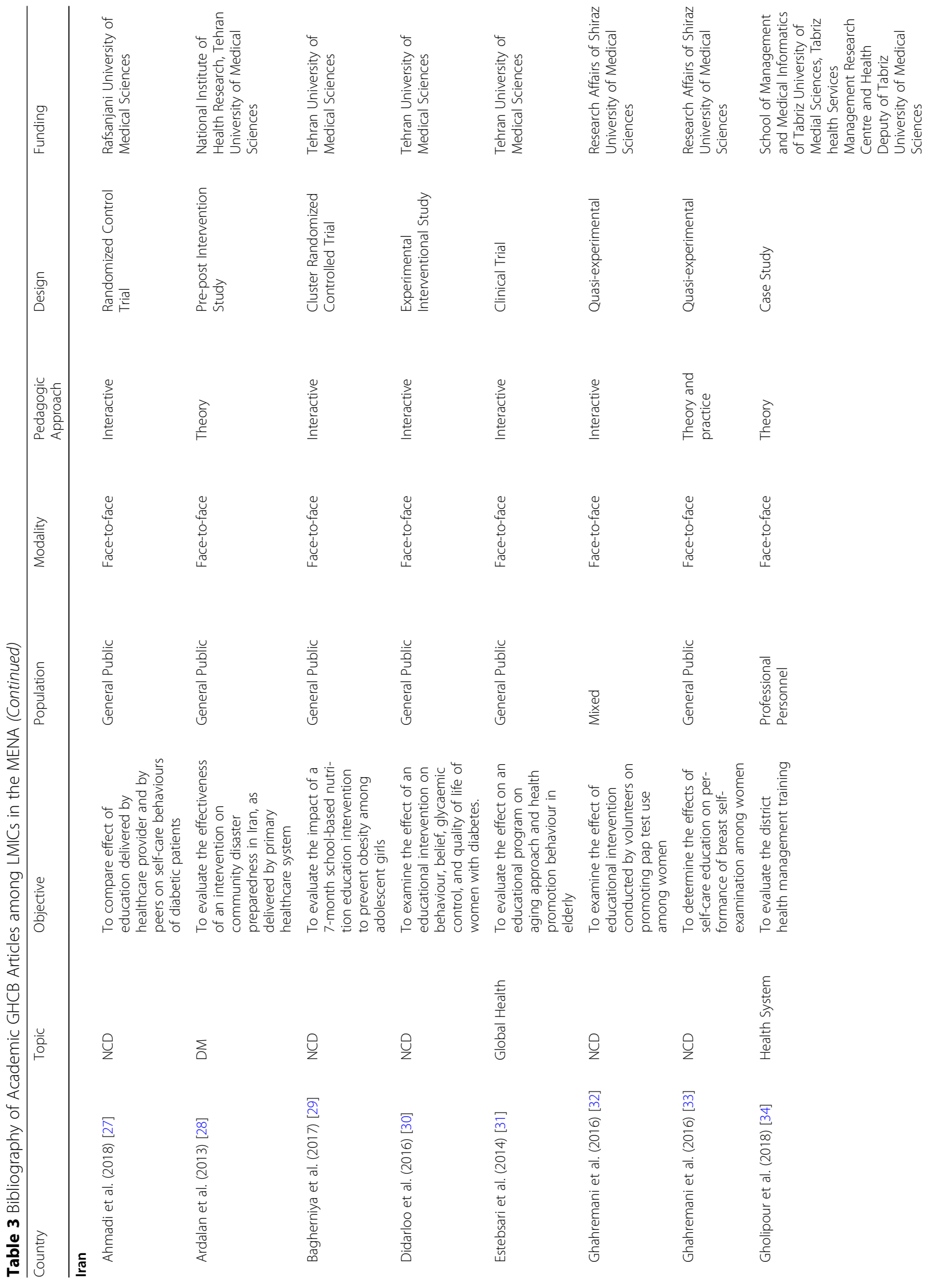




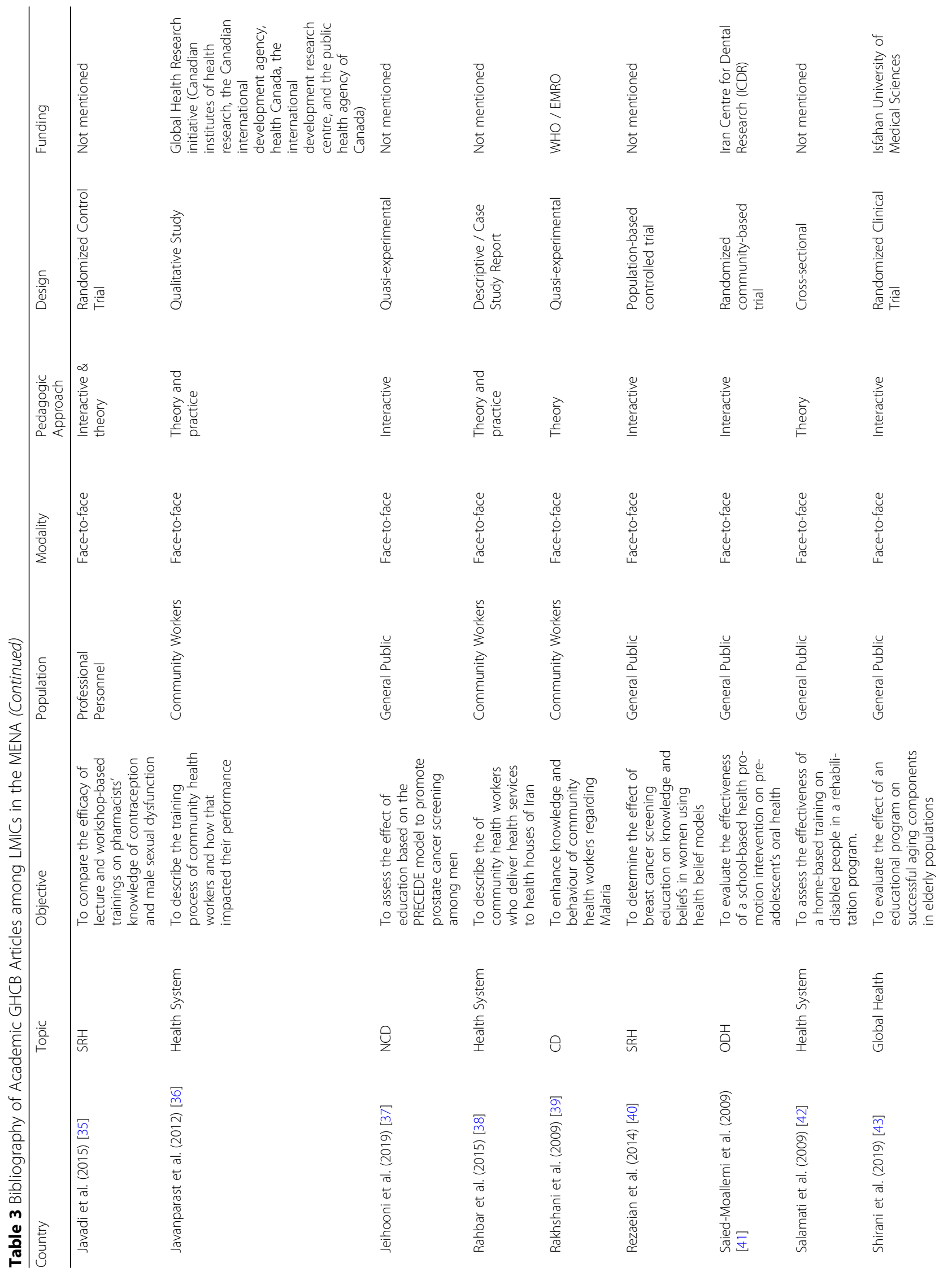




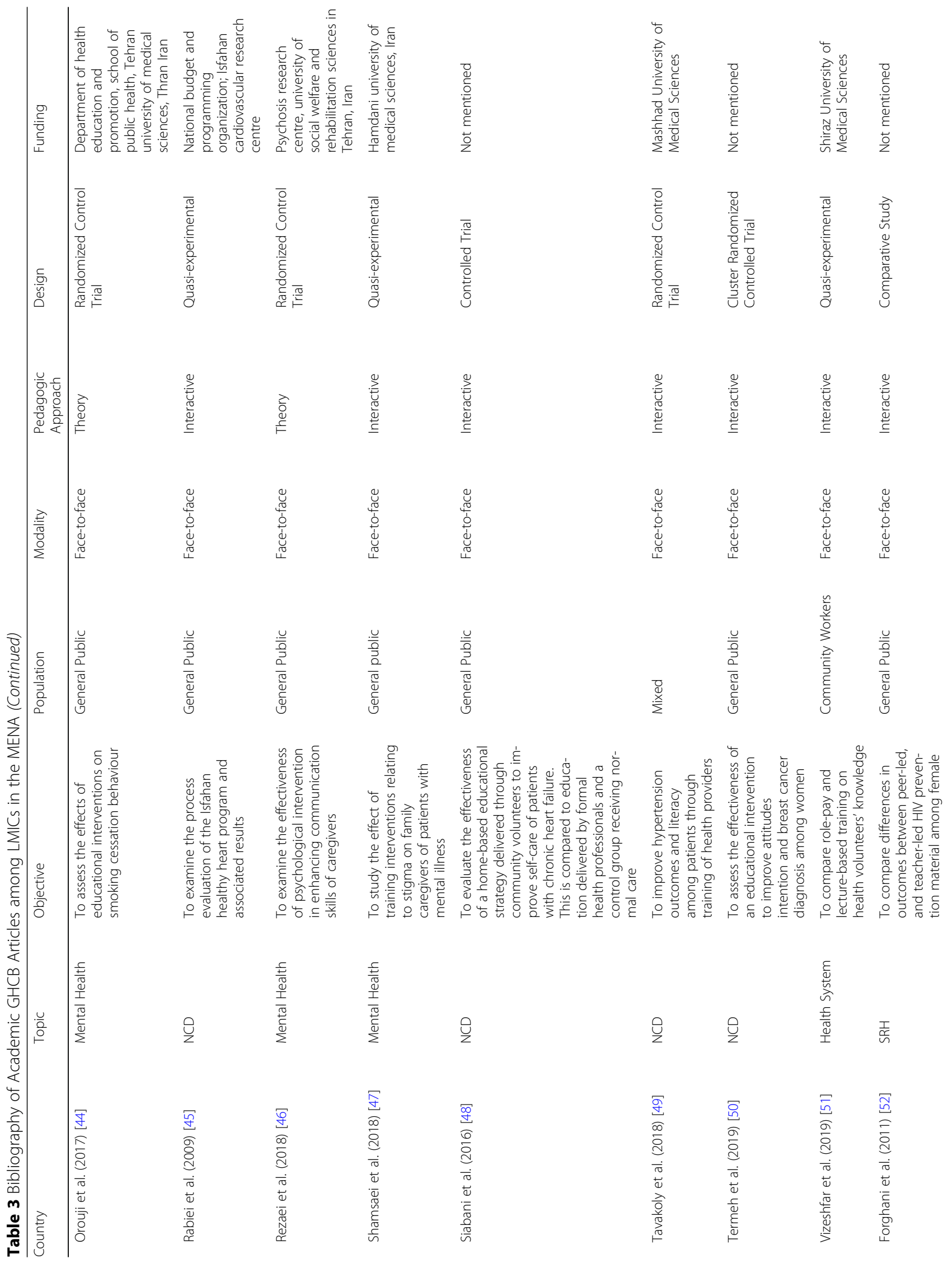




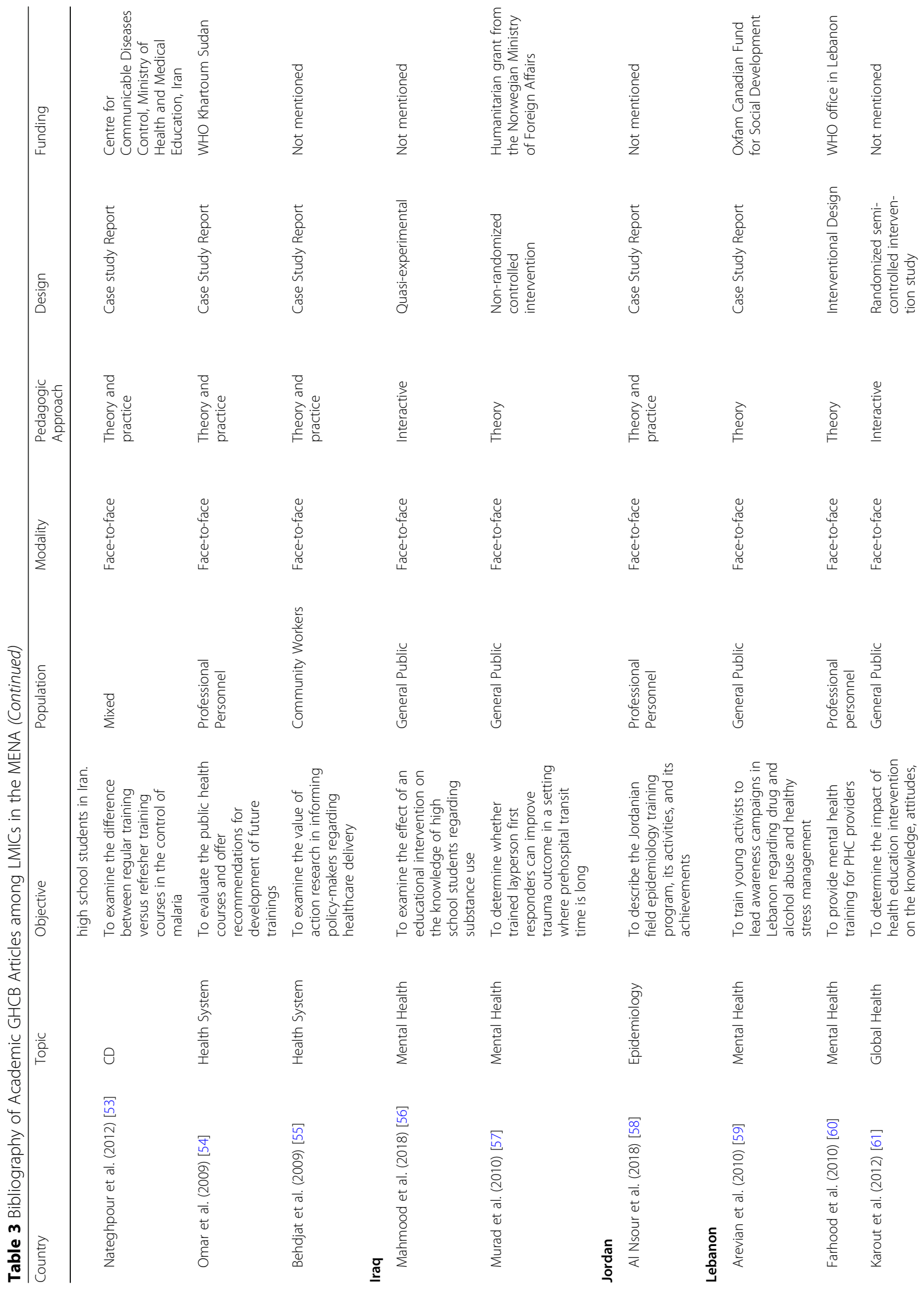




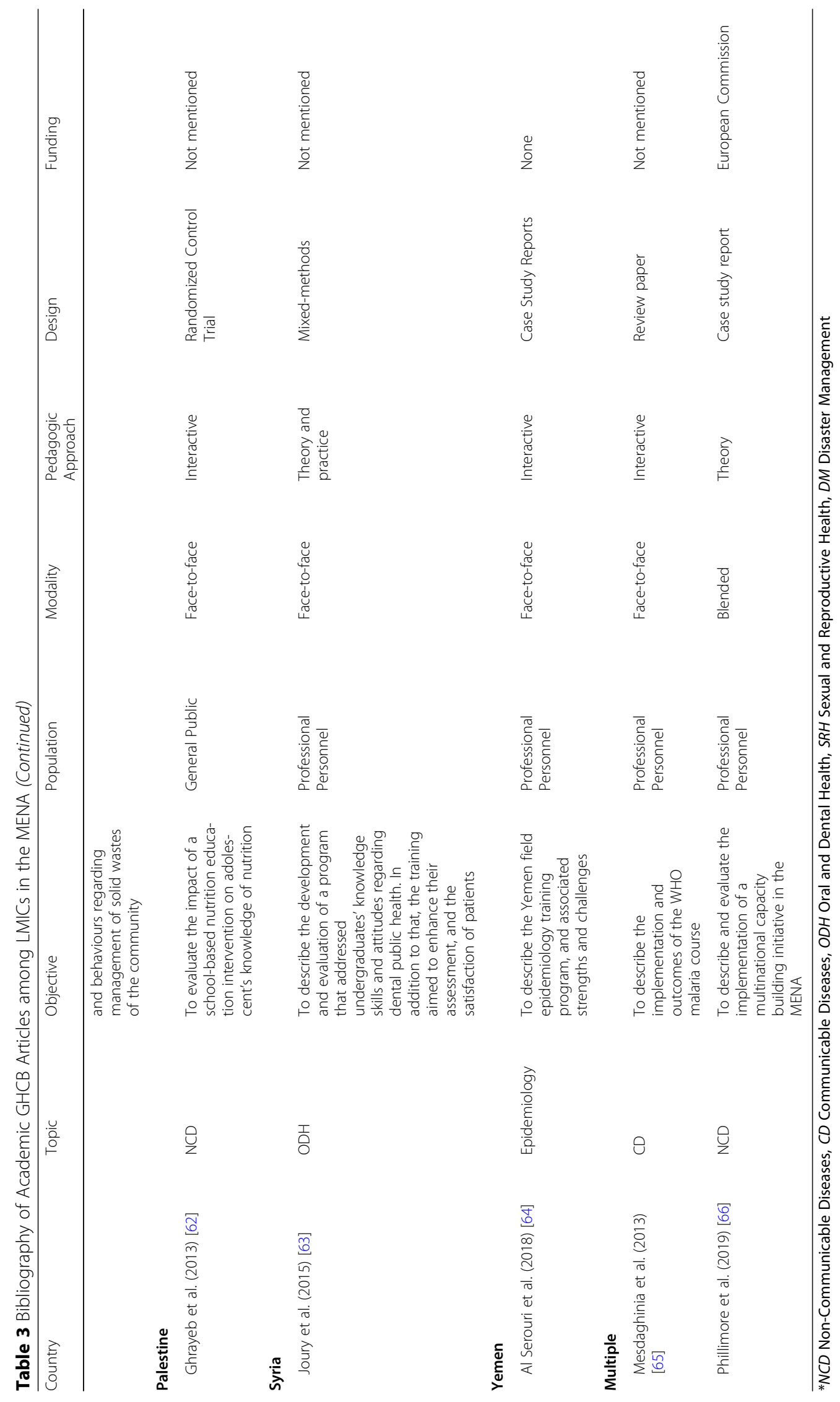




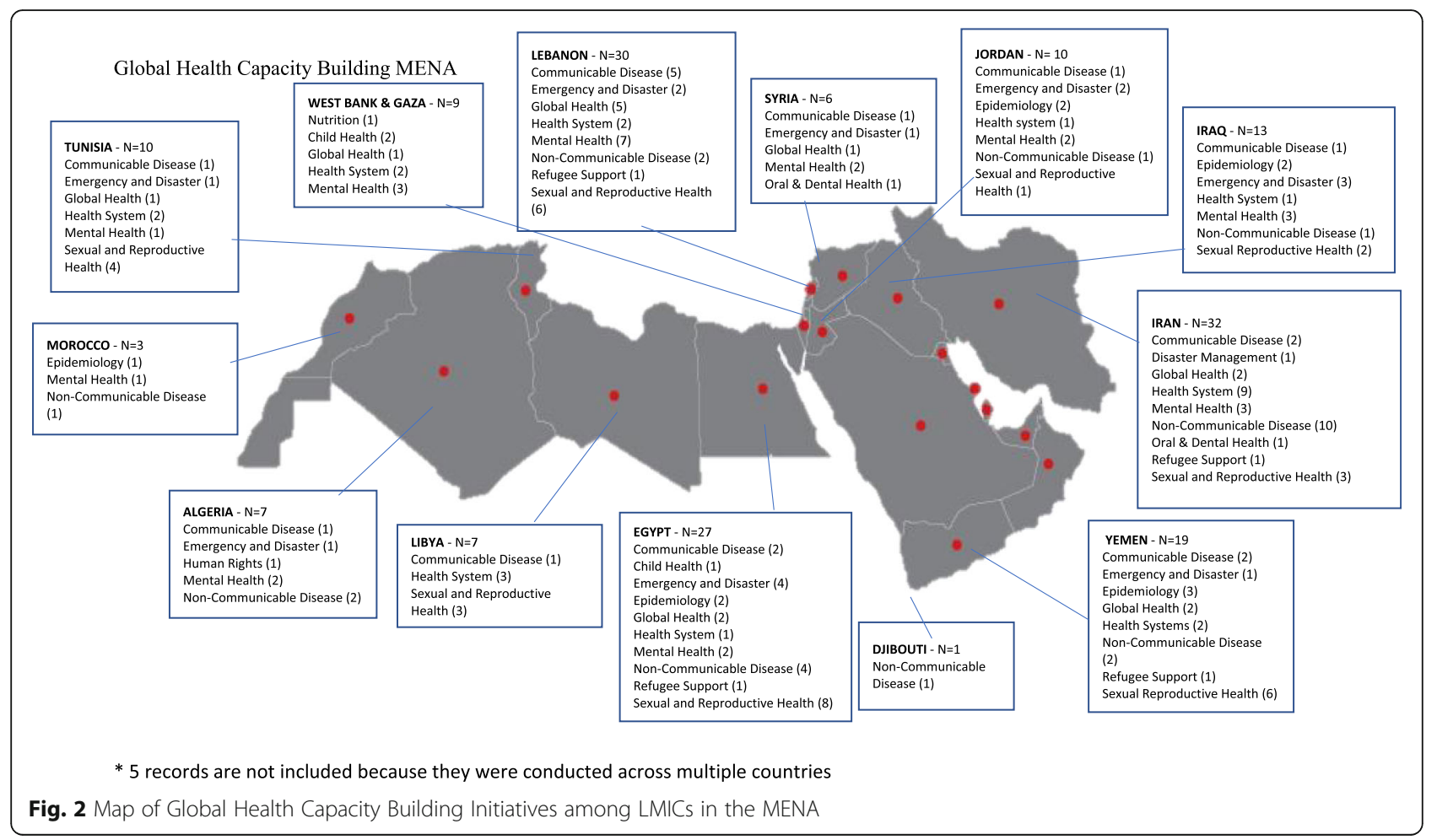

emphasise active learning, it is also important to complement them with hands-on approaches. Accordingly, it may be important to increase GHCB initiatives that include a practicum or practical component, especially that capacity building in this region is necessary to develop the competency of the workforce to deliver healthcare services.

Overall, professional personnel were the main target groups of the GHCB initiatives, and community workers were the least addressed population. While it is expected that most initiatives would be directed towards professionals, it is crucial for future initiatives to place added attention to community workers. Community health workers play a vital role in healthcare systems, especially those in conflict areas with limited resources, since they can provide less expensive and more tailored services to their communities [69]. Research shows that community workers may be very effective for such purposes, and in many instances, may complement the work of professionals in delivering health-related education to members in some communities largely due to the relationships they build with them $[69,70]$.

The most commonly addressed GHCB topics among LMICs in the MENA were categorized under noncommunicable diseases, sexual and reproductive health, and mental health. Although this is congruent with the overall health needs of the MENA region [1, 71, 72], we have identified some important gaps. First, despite the prevalence of GHCB initiatives that target non- communicable diseases, they were concentrated in Egypt and Iran, and they were under-documented in most other countries. It may be important for other countries such as Lebanon, Jordan, Morocco, Tunisia, and Algeria, to implement and report more efforts regarding $\mathrm{GHCB}$ initiatives targeting non-communicable diseases. Second, conflict-related mortalities are among the most common causes of death in the West bank and Gaza, Syria, Libya, Yemen, and Iraq [1, 71], and our results indicate that there is a greater need for emergency and injury-related GHCB in these countries due to their protracted social conflicts. Nevertheless, our findings indicate that mental health GHCB initiatives, which are crucial in war and conflict settings, are commonly reported in some of these countries. Third, although communicable diseases are decreasing overall in the MENA region [1, 71], they still present major concerns in lower-resource settings, and more emphasis should be placed on addressing these topics in countries such as Djibouti.

That said, very few records of GHCB initiatives represented initiatives from Algeria, Djibouti, Libya, Morocco, Syria, and the West Bank and Gaza. These countries, in addition to Jordan, Tunisia, and Yemen, also showed the least academic research activity, given that out of all peer-reviewed articles included in this research, they each had published one or no GHCB study. The majority of initiatives were reported from Egypt, Iran, Lebanon, and Yemen (see Fig. 2). Iran in specific appeared to have the most academic research outputs to 
disseminate GHCB results. Potentially, as indicated by our findings, this may be related to the availability of local funding for their initiatives, as opposed to the rest of the countries who seemed to rely on international funding from HICs. This may be an important indication supporting the need to prioritize the allocation of resources and funding from local sources to encourage the development, implementation, and dissemination of GHCB initiatives. It is probable that due to the limited publications along with the research gaps in this region $[73,74]$, many GHCB initiatives may have not been disseminated in the literature and consequently not reported in this review.

\section{Limitations}

Despite the use of two search strategies from grey and academic sources, some records may have still been missed. For example, some initiatives may have not being reported online or disseminated in the literature, especially those in low-resource settings, which may reduce communication among the global health community and which poses a risk for duplication of efforts and inefficiency. Also, while some distance-learning platforms such as Massive Online Open Courses (MOOCs) and others that are available for worldwide use [68,75], may have reached learners in the MENA region, these were not covered by the scope of our review if they did not explicitly report implementation in a LMIC in the MENA region. Furthermore, some countries in the MENA region may have a lower technical capacity or may be less inclined to allocate resources to publish research outputs. Taken together, these limitations highlight the need to support LMICs in the MENA region to enhance their research production. Additionally, the fact that we only included English records may have limited our range of reviewed records. It is also important to consider that some capacity building records may have not been disseminated under the term "Global Health", which may have influenced the search and screening process. Finally, although efforts may have been directed to each country's health needs, we only reviewed records that had a training and/or educational component, and so initiatives such as awareness campaigns and others were not included in this review.

\section{Conclusion}

In light of the escalating global health challenges among LMICs in the MENA region, this systematic review presents the first timely summary and comprehensive analysis of GHCB initiatives being conducted in this setting. Several critical points were identified from this review, such that more GHCB initiatives targeting NCDs and emergency-related topics are needed for most of the reviewed countries. It is also important for this region to increase their adoption of innovative learning modalities and practical and hands-on approaches, and to target more community health workers. Finally, it may be essential for countries to prioritize and mobilise resources and local funding to increase the development, implementation, and dissemination of GHCB initiatives.

\section{Supplementary information}

Supplementary information accompanies this paper at https://doi.org/10. 1186/s12992-020-00585-0.

Additional file 1. Search Strategy.

Additional file 2. Bibliography of Grey Literature GHCB sources among LMICs in the MENA

\section{Acknowledgments}

Authors acknowledge the help of Ms. Rania Mansour in preparing the tables for the grey literature sources.

\section{Authors' contributions}

$\mathrm{HN}, \mathrm{MEH}, \mathrm{MEK}$, and SS designed the study. LH conducted the search process from the academic databases, and $\mathrm{MEH}$ conducted the search process from the grey sources. HN, MEH, MEK screened articles. HN analysed the data and wrote the manuscript with input from MEK. MEK and SS provided critical comments and revisions and oversaw the project. The authors read and approved the final manuscript.

\section{Funding}

This research was funded by the International Development Research Center (IDRC) Canada. The funders did not have any role in the design of the study and collection, analysis, and interpretation of data and in writing the manuscript.

\section{Availability of data and materials}

The datasets used and/or analysed during the current study are available from the corresponding author on reasonable request.

Ethics approval and consent to participate

Not applicable.

Consent for publication

Not applicable.

\section{Competing interests}

The authors declare that they have no competing interests.

\section{Author details}

${ }^{1}$ Global Health Institute at the American University of Beirut, Faculty of Health Sciences at the American University of Beirut, Beirut, Lebanon. ${ }^{2}$ Saab Medical Library at the American University of Beirut, Beirut, Lebanon.

Received: 12 March 2020 Accepted: 17 June 2020

Published online: 03 July 2020

\section{References}

1. Evaluation. IfHM, Network. HD, Bank. TW. The Global Burden of Disease: Generating Evidence, Guiding Policy - Middle East and North Africa Regional Edition. Seattle, WA: IHM; 2013.

2. Organization WH. Global strategy on human resources for health: workforce 2030. Geneva: WHO; 2016.

3. Miseda M, Were S, Murianki C, Mutuku M, Mutwiwa S. The implication of the shortage of health workforcce specialist on universal health coverage in Kenya. Human Resour Health. 2017;15(80):1-7.

4. Crisp N, Chen L. Global supply of health professionals. N Engl J Med. 2014; 370(10):950-7.

5. Holt G, McMains K, Otto R. Workforce considerations, Training, and Diseases in the Middle East. Otolaryngol Clin North Am. 2018;51:667-73. 
6. Mormina M, Pinder S. A conceptual framework for training of trainers (ToT) interventions in global health. Global Health. 2018;14(1).

7. Cancedda C, Farmer P, Kerry V, Nuthulaganti T, Scott K, Goosby E, et al. Maximizing the Impact of Training Initiatives for Health Professionals in Low-Income Countries: Frameworks, Challenges, and Best Practices. PLoS Med. 2015;12(6):e1001840-e.

8. Rabbani F, Shipton L, White F, Nuwayhid I, London L, Ghaffar A, et al. School of public health in low and middle-income countries: an imperative investment for improving the health of populations? BMC Public Health 2016;16(941):1-12.

9. Long L, Pariyo G, Kallander K. Digital Technologies for Health Workforce Development in low- and middle-income countries: a scoping review. Glob Health Sci Pract. 2018:S41-S8.

10. Celletti F, Reynolds T, Wright A, Stoertz A, Dayrit M. Educating a new generation of doctors to improve the health of populations in low- and middle-income countries. PLoS Med. 2011;8(10):e1001108.

11. Kislov R, Waterman H, Harvey G, Boaden R. Rethinking capacity building for knowledge mobilisation: developing multilevel capabilities in healthcare organisations. Implement Sci. 2014;9(166):1-12.

12. Koplan J, Bond C, Merson M, Reddy S, Rodriguez M, Sewankambo N, et al. Towards a common definition of global health. Lancet. 2009:373.

13. Beran D, Byass P, Gbakima A, Kahn K, Sankoh O, Tollman S, et al. Research Capacity Building - obligations for global health partners. Lancet Glob Health. 2017;5:e567-e8.

14. DeCorby-Watson K, Mensah G, Bergeron K, Abdi S, Rempel B, Manson H. Effectiveness of capacity building interventions relevant to public health practice: a systematic review. BMC Public health. 2018;18(684).

15. WorldBank. Classifying countries by income 2019 [Available from: http:// datatopics.worldbank.org/world-development-indicators/stories/theclassification-of-countries-by-income.html.

16. Institute of Medicine. America's vital interest in global health: protecting our people, enhancing our economy, and advancing our international interests. Washington (DC): Institute of Medicine - National Academy Press; 1997.

17. Smith J, Tang C, Nutbeam D. WHO health promotion glossary: new terms. Health Promotion International. 2006;21(4):340-5.

18. Organization WH. Mapping and analysis of capacity building initiatives on human resources for health leadership. Geneva: WHO; 2017.

19. Abdel-Aziz SB, Mowafy MA, Galal YS. Assessing the impact of a communitybased health and nutrition education on the Management of Diarrhea in an Urban District, Cairo, Egypt. Global J Health Sci. 2015;8(2):46-55.

20. Abdelazim SA, Nour-Eldein H, Ismail MA, Al Sayed Fiala L, Abdulmajeed AA. Effect of training program regarding smoking cessation counseling for primary health care physicians in Port Said City, Egypt. J Public Health (Germany). 2018;26(5):569-75.

21. Abdelhai R, Yassin S, Ahmad MF, Fors UG. An e-learning reproductive health module to support improved student learning and interaction: a prospective interventional study at a medical school in Egypt. BMC Med Educ. 2012;12:11

22. Alfaar AS, Kamal S, Abouelnaga S, Greene WL, Quintana Y, Ribeiro RC, et al. International telepharmacy education: another venue to improve cancer care in the developing world. Telemed J E-Health. 2012;18(6): 470-4.

23. El Nouman A, El Derwi D, Abdel HR, Abou ZH. Female youth health promotion model in primary health care: a community-based study in rural upper Egypt. East Mediterr Health J. 2009;15(6):1513-24.

24. El-Sayed H, Martines J, Rakha M, Zekry O, Abdel-Hak M, Abbas H. The effectiveness of the $\mathrm{WHO}$ training course on complementary feeding counseling in a primary care setting, Ismailia, Egypt. J Egypt Public Health Assoc. 2014;89(1):1-8.

25. El-Shinawi M, McCunn M, Sisley AC, El-Setouhy M, Hirshon JM. Developing sustainable trauma care education in Egypt: sequential trauma education program, steps to success. J Surg Educ. 2015;72(4):e29-32.

26. Roess A, Lahm S, Kabbash I, Saad-Hussein A, Shaalan A, Rasslan O, et al. Responding to emerging diseases requires multi-disciplinary and one health training. Egypt Ann Glob Health. 2018;84(4):650-3.

27. Ahmadi Z, Sadeghi T, Loripoor M. The outcomes of peer-led diabetes education in comparison to education delivered by health professionals in Iranian patients. Health Educ Res. 2018;33(1):64-72.

28. Ardalan A, Mowafi H, Malekafzali Ardakani H, Abolhasanai F, Zanganeh AM, Safizadeh $\mathrm{H}$, et al. Effectiveness of a primary health care program on urban and rural community disaster preparedness, Islamic Republic of Iran: a community intervention trial. Disast Med Public Health Preparedness. 2013; 7(5):481-90.

29. Bagherniya M, Sharma M, Mostafavi Darani F, Maracy MR, Safarian M, Allipour Birgani R, et al. School-based nutrition education intervention using social cognitive theory for overweight and obese Iranian adolescent girls: a cluster randomized controlled trial. Int Quart Commun Health Educ. 2017; 38(1):37-45.

30. Didarloo A, Shojaeizadeh D, Alizadeh M. Impact of educational intervention based on interactive approaches on beliefs, behavior, hemoglobin a1c, and quality of life in diabetic women. International Journal of Preventive Medicine. 2016;2016(FEBRUARY).

31. Estebsari F, Taghdisi MH, Rahimi Foroushani A, Eftekhar Ardebili $H_{\text {, }}$ Shojaeizadeh D. An educational program based on the successful aging approach on health-promoting behaviors in the elderly: a clinical trial study. Iran Red Crescent Med J. 2014;16(4):e16314.

32. Ghahremani L, Harami ZK, Kaveh MH, Keshavarzi S. Investigation of the role of training health volunteers in promoting pap smear test use among Iranian women based on the protection motivation theory. Asian Pac J Cancer Prevent. 2016:17(3):1157-62.

33. Ghahremani L, Mousavi Z, Kaveh MH, Ghaem H. Self-care education programs based on a trans-theoretical model in women referring to health centers: breast self-examination behavior in Iran. Asian Pac J Cancer Prevent 2016;17(12):5133-8.

34. Gholipour K, Tabrizi JS, Farahbakhsh M, lezadi S, Ghiasi A, Jahanbin H. Evaluation of the district health management fellowship training programme: a case study in Iran. BMJ Open. 2018;8(3):e020603.

35. Javadi M, Kargar A, Gholami K, Hadjibabaie M, Rashidian A, Torkamandi H, et al. Didactic lecture versus interactive workshop for continuing pharmacy education on reproductive health: a randomized controlled trial. Eval Health Prof. 2015;38(3):404-18.

36. Javanparast S, Baum F, Labonte R, Sanders D, Rajabi Z, Heidari G. The experience of community health workers training in Iran: a qualitative study. BMC Health Serv Res. 2012;12:291.

37. Jeihooni AK, Kashfi SM, Hatami M, Avand A, Bazrafshan MR. The effect of educational program based on PRECEDE model in promoting prostate Cancer screening in a sample of Iranian men. J Cancer Educ. 2019;34(1):161-72.

38. Rahbar M, Ahmadi M. Lessons Learnt From the Model of Instructional System for Training Community Health Workers in Rural Health Houses of Iran. Iran Red Crescent Med J. 2015;17(2).

39. Rakhshani F, Mohammadi M. Improving community health Workers' knowledge and behaviour about proper content in malaria education. J Pak Med Assoc. 2009;59(6):395-8.

40. Rezaeian M, Sharifirad G, Mostafavi F, Moodi M, Abbasi MH. The effects of breast cancer educational intervention on knowledge and health beliefs of women 40 years and older, Isfahan. Iran J Educ Health Promot. 2014;3:43.

41. Saied-Moallemi Z, Virtanen II, Vehkalahti MM, Tehranchi A, Murtomaa H. School-based intervention to promote preadolescents' gingival health: a community trial. Community Dentistry Oral Epidemiol. 2009;37(6):518-26.

42. Salamati P, Abolhassani F, Shariati B, Kamali M, Alehossein SM. Home based training: Main strategy of community based rehabilitation in Iran. Pak J Med Sci. 2009;25(3):462-7.

43. Shirani M, Kheirabadi G, Sharifirad G, Keshvari M. The effect of education program on health promotion behavior on successful aging. Iran J Nurs Midwifery Res. 2019;24(3):234-8.

44. Orouji MA, Shojaeizadeh D, Sadeghi R, Rafiei M. Effects of a theory-driven educational package and social support on durability of cigarette smoking cessation behavior: a community-based program. Electronic Phys. 2017;9(9): 5331-8.

45. Rabiei K, Kelishadi R, Sarrafzadegan N, Abedi HA, Alavi M, Heidari K, et al. Process evaluation of a community-based program for prevention and control of non-communicable disease in a developing country: the Isfahan healthy heart program, Iran. BMC Public Health. 2009;9.

46. Rezaei O, Bayani A, Mokhayeri Y, Waye K, Sadat Y, Haroni J, et al. Applying psychoeducational program on general health and communication skills in caregivers of patients with schizophrenia: a randomized controlled trial. Eur J Psychiatr. 2018;32(4):174-81.

47. Shamsaei F, Nazari F, Sadeghian E. The effect of training interventions of stigma associated with mental illness on family caregivers: A quasiexperimental study 11 Medical and Health Sciences 1117 Public Health and Health Services. Ann Gen Psychiatr. 2018;17(1). 
48. Siabani S, Driscoll T, Davidson PM, Leeder SR. Efficacy of a home-based educational strategy involving community health volunteers in improving self-care in patients with chronic heart failure in western Iran: a randomized controlled trial. Eur J Cardiovasc Nurs. 2016;15(5):363-71.

49. Tavakoly Sany SB, Peyman N, Behzhad F, Esmaeily H, Taghipoor A, Ferns G. Health providers' communication skills training affects hypertension outcomes. Med Teach. 2018;40(2):154-63.

50. Termeh Zonouzy V, Niknami S, Ghofranipour F, Montazeri A. An educational intervention based on the extended parallel process model to improve attitude, behavioral intention, and early breast cancer diagnosis: a randomized trial. Int J Women's Health. 2019:11:1-10.

51. Vizeshfar F, Zare M, Keshtkaran Z. Role-play versus lecture methods in community health volunteers. Nurse Educ Today. 2019;79:175-9.

52. Forghani H. Peer-led versus teacher-led AIDS education for female high schools students in Yazd, Iran. J Sex Med. 2011:8:249.

53. Nateghpour M, Edrissian G, Raeisi A, Motevalli-Haghi A, Farivar L, Mohseni G, et al. The Role of Malaria Microscopy Training and Refresher Training Courses in Malaria Control Program in Iran during 2001-2011. Iran J Parasitol. 2012;7(4):104-9.

54. Omar M, Gerein N, Tarin E, Butcher C, Pearson S, Heidari G. Training evaluation: a case study of training Iranian health managers. Hum Resour Health. 2009;7.

55. Behdjat H, Rifkin SB, Tarin E, Sheikh MR. A new role for women health volunteers in urban Islamic Republic of Iran. East Mediterr Health J. 2009; 15(5):1164-73.

56. Mahmood N, Othman S, Al-Tawil N, Al-Hadithi T. Impact of an education intervention on knowledge of high school students concerning substance use in Kurdistan Region-Iraq: A quasi-experimental study. PloS One. 2018; 13(10).

57. Murad MK, Husum $\mathrm{H}$. Trained lay first responders reduce trauma mortality: a controlled study of rural trauma in Iraq. Prehosp Disast Med. 2010;25(6):533-9.

58. Al Nsour M, Iblan I, Tarawneh MR. Jordan field epidemiology training program: critical role in national and regional capacity building. JMIR Med Educ. 2018;4(1):e12.

59. Arevian M. Training trainees, young activists, to conduct awareness campaigns about prevention of substance abuse among Lebanese/ Armenian young people. J Interprof Care. 2010;24(2):173-82.

60. Farhood L. Mental Health and Psychosocial Care for Citizens Affected by War in Lebanon: Training Project for Healthcare Professionals. In: Wiederhold BK, editor. Coping with Posttraumatic Stress Disorder in Returning Troops: Wounds of War li. Nato Science for Peace and Security Series E-Human and Societal Dynamics. 68;2010:263-276.

61. Karout N, Altuwaijri S. Impact of health education on community knowledge, attitudes and behaviour towards solid waste management in Al Ghobeiry, Beirut. East Mediterranean Health J. 2012;18(7):777-85.

62. Ghrayeb FAW, Rusli MA, Al Rifai A, Ismail MI. Effectiveness of nutrition education intervention among high school students in Tarqumia, Palestine. Pak J Nutr. 2013;12(8):787-92.

63. Joury E. Community-based learning in a challenging context: the development and evaluation of an outreach dental public health programme in Damascus University, Syria. Eur J Dental Educ. 2016;20(1):39-44.

64. Al Serouri A, Jumaan A, Alkohlani A. Yemen field epidemiology training programme: a tool for strengthening the public health workforce. East Mediterr Health J. 2018;24(9):905-13.

65. Mesdaghinia AR, Vatandoost $H$, Hanafi-Bojd AA, Majdzadeh $R$, Raeisi A. Conducting international diploma course on malaria program planning and management (1996-2012). J Arthropod Borne Dis. 2013:7(2):100-12.

66. Phillimore P, Sibai AM, Rizk A, Maziak W, Unal B, Abu Rmeilehe N, et al. Context-led capacity building in time of crisis: fostering non-communicable diseases (NCD) research skills in the Mediterranean Middle East and North Africa. Glob Health Act. 2019;12(1).

67. McConnell K, Lenssen M, Bunik M, Bunge Montes S, Domek G. Telehealth to expand community health nurse education in rural guatemala: a pilot feasibility and acceptability evaluation. Front Public Health. 2017:5(60).

68. Clair V, Rossa-Roccor V, Mokaya A, Mutiso V, Musau A, Tele A, et al. Peerand Mentor-Enhanced Web-Based Training on Substance Use Disorders: A Promising Approach in Low-Resource Settings. Psychatr Serv. 2017;70(11): 1068-71.

69. Scott K, Beckham S, Gross M, George P, Rao K, Cometto G, et al. What do we know about community-based health workers programs? A systematic review of existing reviews on community health workers. Amsterdam: Human Resour Health. 2018;16(39):1-17.

70. Sarli L, Enongene E, Bulgarelli K, Sarli A, Renda A, Sansebastiano G, et al. Training program for community health workers in remote areas in Senegal First Experience. Acta BioMed. 2010;81:54-62.

71. Evaluation. IfHMa. GBD Compare Seattle, WA: IHME; 2017 [Available from: http://vizhub.healthdata.org/gbd-compare.

72. El Arnaout N, Rutherford S, Zreik T, Nabulsi D, Yassin N, Saleh S. Assessment of the health needs of Syrian refugees in Lebanon and Syria's neighboring countries. Confl Heal. 2019;13(31):1-14.

73. El-Jardali F, Jamal D, Ataya N, Jaafar M, Raouf S, Matta C, et al. Health policy and systems research in twelve eastern Mediterranean countries: a stocktaking of production and gaps (2000-2008). Health Res Policy Syst. 2011;9(39):1-12.

74. El-Achi N, Papamichail A, Rizk A, Lindsay H, Menassa M, Abdul-Khalek R, et al. A conceptual framework for capacity strengthening of health research in conflict: the case of the middle east and north africa region. Global Health. 2019;15(81):1-15.

75. Rossa-Roccor VM, Frank EL. NextGenU.org's Free, Globally Available Online Training in Lifestyle Medicine. Am J Lifestyle Med. 2017:132-3.

\section{Publisher's Note}

Springer Nature remains neutral with regard to jurisdictional claims in published maps and institutional affiliations.
Ready to submit your research? Choose BMC and benefit from:

- fast, convenient online submission

- thorough peer review by experienced researchers in your field

- rapid publication on acceptance

- support for research data, including large and complex data types

- gold Open Access which fosters wider collaboration and increased citations

- maximum visibility for your research: over $100 \mathrm{M}$ website views per year

At BMC, research is always in progress.

Learn more biomedcentral.com/submissions 